\title{
CARS Temperature and Species Concentration Measurements in a Supersonic Combustor with Normal Injection
}

\author{
S. A. Tedder \\ NASA Langley Research Center, Hampton VA, 23681 \\ S. O’Byrne ${ }^{\dagger}$ \\ UNSW@ADFA, Canberra,ACT,2600,Australia \\ P. M. Danehy \\ NASA Langley Research Center, Hampton, VA, 23681 \\ A. D. Cutler ${ }^{\S}$ \\ The George Washington University, Hampton, VA, 23681
}

The dual-pump coherent anti-Stokes Raman spectroscopy (CARS) method was used to measure temperature and the absolute mole fractions of $\mathrm{N}_{2}, \mathrm{O}_{2}$ and $\mathrm{H}_{2}$ in a supersonic combustor. Experiments were conducted in the NASA Langley Direct-Connect Supersonic Combustion Test Facility. CARS measurements were performed at the facility nozzle exit and at three planes downstream of fuel injection. Processing the CARS measurements produced maps of the mean temperature, as well as quantitative $\mathrm{N}_{2}$ and $\mathrm{O}_{2}$ and qualitative $\mathrm{H}_{2}$ mean mole fraction fields at each plane. The CARS measurements were also used to compute correlations between fluctuations of the different simultaneously measured parameters. Comparisons were made between this $90^{\circ}$ angle fuel injection case and a $30^{\circ}$ fuel injection case previously presented at the 2004 Reno AIAA Meeting.

\section{Introduction}

Future improvements in supersonic combustion engine design require a greater understanding of the complex interaction between turbulent mixing and chemical reaction occurring within the combustor. Measurements of the flow inside the combustor can be challenging to obtain because of the extreme operating environment. For example, combustion temperatures within the duct can approach $3000 \mathrm{~K}$. Additional challenges are presented by the fact that any flow measurement must be obtained in a non-intrusive fashion, as intrusive probes would destructively perturb the flow and not survive the operating environment.

A non-invasive measurement known as coherent anti-Stokes Raman scattering (CARS) ${ }^{1,2,3,4,5,6,7}$ can meet these challenges and has been used in the current experiment. This system can simultaneously measure the temperature and species mole fractions of the combustor gases. Other techniques such as Raman scattering can measure the same quantities, but CARS has the advantage of producing a coherent signal beam, which increases the signal-tonoise ratio of measurements and permits spatial filtering to reduce the degradation of measurement quality due to interference from flow luminosity. The coherent nature of the CARS signal also means that measurements can be made where optical access to the flow is limited, such as in ducts. CARS can be used to assess the effects of the change in experimental variables such as geometry, fuel-air ratio, flight enthalpy and fuel injection angle.

This paper is one of a series of papers from NASA Langley Research Center that describe CARS measurements in a supersonic combustor ${ }^{6,7,8}$. The previous studies concerned the injection of $\mathrm{H}_{2}$ fuel into the combustor at 30 degrees to the wall. Although the enthalpy of the combustion-heated air-simulant was that of Mach $7 \mathrm{flight}$, the

\footnotetext{
${ }^{*}$ Graduate Co-op Student at NASA Langley Research Center and Graduate Student at College of William and Mary

${ }^{\dagger}$ Postdoctoral Fellow, Member AIAA, formerly NRC Postdoctoral Fellow at NASA Langley Research Center

${ }^{\sharp}$ Research Scientist, Associate Fellow AIAA

${ }^{\S}$ Associate Professor, Associate Fellow AIAA

Copyright (C) 2005 by the American Institute of Aeronautics and Astronautics Inc. The U.S. Government has a royalty-free license to exercise all rights under the copyright claimed herein for Governmental purposes. All other rights are reserved by the copyright owner.
} 
combustion of the fuel did not begin to occur until well downstream of the injection point. The prediction of this behavior has proved difficult for CFD modelers. ${ }^{9}$ In the present study, fuel is injected normal to the surface. This form of injection, in conjunction with a backward facing step, sets up a region of recirculating flow in the vicinity of the step and injector that holds the flame to the step.

The dual-pump CARS method originally developed by Lucht and co-workers ${ }^{10,11}$ was used to simultaneously measure temperature and the absolute mole fractions of $\mathrm{N}_{2}$ and $\mathrm{O}_{2}$. We have extended Lucht's approach to measure $\mathrm{H}_{2}$ as well, as described in Ref. 8 and Ref. 12. The collected spectra are fitted to a theoretical model on a computer in order to determine the flow properties. Each of the measurements is then combined with the other points within the same plane to create surface maps for each of the four planes. Since the flow properties are measured simultaneously, correlations can be made between the different properties. This data can then be compared to the previously performed experiment with vectored fuel injection ${ }^{8}$ and the effects of the fuel injection angle are assessed.

\section{Combustor Model and Flow Facility}

The experiment was conducted in the NASA Langley Direct-Connect Supersonic Combustion Test Facility (DCSCTF). The facility is designed to test the combustor of a scramjet engine by directly connecting the facility nozzle exit to the entrance of the combustor. Air, $\mathrm{H}_{2}$, and $\mathrm{O}_{2}$ are reacted in proportions such that the enthalpy of the products is that of the flight Mach number being simulated, and the free oxygen content is that of standard air. This high-pressure, vitiated gas is accelerated through a water-cooled convergent-divergent Mach 2 nozzle, before entering the test model.

The test enthalpy was originally planned to be that of Mach 7 flight in order to be directly comparable to the vectored fuel injection case $e^{6,7,8}$. Upon initial testing, normal fuel injection produced high combustor temperatures and pressures that caused the test model to deform slightly, causing test gases to leak from the model seams. Consequently, the test conditions were set to an equivalent Mach 6 enthalpy condition, and a target equivalence ratio of 0.7 achieved by lowering the flow rate of the $\mathrm{H}_{2}$. All test conditions that follow in this section were the target test conditions. Gas flow rates to the heater were: $1.169 \pm 0.006 \mathrm{~kg} / \mathrm{s}$ air, $0.0231 \pm 0.0006 \mathrm{~kg} / \mathrm{s} \mathrm{H_{2 }}$, and $0.281 \pm 0.003 \mathrm{~kg} / \mathrm{s}$ $\mathrm{O}_{2}$. The heater stagnation pressure was $0.795 \pm 0.015 \mathrm{MPa}$. All uncertainties presented in this paper are based on $95 \%$ probability limits (1.96 times the standard deviation). The above uncertainties are due to random run-to-run variations and do not include $\pm 3 \%$ uncertainty in the mass flow rate measurements.

Heater and nozzle exit conditions were computed from the flow rates, heater pressure, and nozzle minimum and exit areas using one-dimensional (1D) analysis detailed in Ref. 13. The nominal calculated conditions, and uncertainties due to mass flow rate measurement error and run-to-run variations in heater conditions were: heater stagnation temperature $1490 \pm 75 \mathrm{~K}$, estimated exit static temperature $926 \pm 60 \mathrm{~K}$, exit pressure $101 \pm 1.5 \mathrm{kPa}$, exit Mach number $2.007 \pm 0.005$. Errors arising from the assumption of 1D flow (the effects of non-uniform composition, boundary layers, etc.) are neglected. A study of the flow quality at the exit of the facility nozzle was previously conducted and is described in Ref. 14.

The combustor model, known as the SCHOLAR model, is shown in Fig. 1; flow direction is from left to right. The model consists of two main sections of duct: a copper upstream section and a carbon steel downstream section. Stainless steel flanges and carbon gaskets separate the sections from each other and from the nozzle. Proceeding from left to right, there is a Mach 2 nozzle, a constant area segment, a small outward step at the top wall, a second short constant-area segment and a segment with constant $3^{\circ}$ divergence of the top wall. The span is constant at $87.88 \mathrm{~mm}$. The injector is a sonic orifice as opposed to a contoured throat as in Ref. 8. Hydrogen is injected at a stagnation (a)
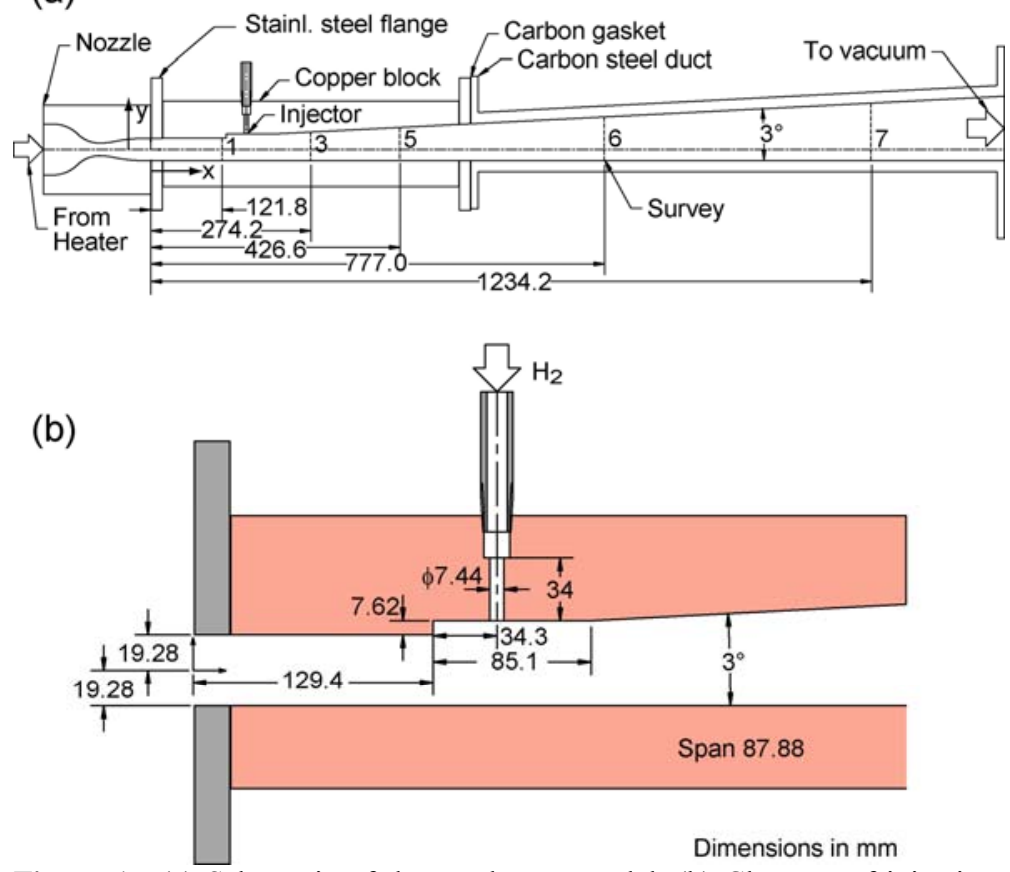

Figure 1. (a) Schematic of the combustor model. (b) Close-up of injection region. All dimensions are in $\mathrm{mm}$. 
pressure of $1.35 \pm 0.025 \mathrm{MPa}$ and a stagnation temperature of $290 \pm 5 \mathrm{~K}$. This fuel-flow rate corresponds the overall target equivalence ratio of 0.7 for the gas in the duct.

The model is uncooled; however, the wall thickness of the copper duct is greater than $32 \mathrm{~mm}$ and the carbon steel duct is 19-mm thick. It is possible to operate the facility at Mach 6 flight conditions with the model fueled for run times in excess of 20 seconds without exposing the combustor to damage from excessive heating. With atmospheric temperature air flowing in the model between runs to cool the engine, tests can be repeated every 10-15 minutes. A total of 15-25 runs could be obtained per day.

The model is equipped with 7 slots to allow the CARS beams to penetrate the duct. The first slot is at the nozzle exit and the other 6 slots are downstream of the fuel injection, as shown in Fig. 1. Slots 1, 3, 6, and 7 were used in this study. The slots are used in pairs, one on each side of the duct. They are $4.8 \mathrm{~mm}$ wide and extend the full height of the duct. When not in use, the slots are plugged flush to the duct wall. Windows covering the slots are mounted at the end of short rectangular tubes at the Brewster angle, to minimize reflections. The tubes connecting the windows and combustor are ventilated with a constant flow of electrically heated ( $400 \mathrm{~K})$ dry air to prevent condensation of water from the heater on the windows. The CARS interaction region can be translated the full span and height of the duct without damaging the windows. The combustor model is also instrumented with both pressure taps and wall temperature probes.

\section{CARS Experimental System}

The dual-pump CARS system used an unseeded, frequency-doubled Nd:YAG laser (Spectra Physics DCR-4), producing about $550 \mathrm{~mJ}$ per pulse at $532 \mathrm{~nm}$. The pulse duration was $10 \mathrm{~ns}$ and the repetition rate was $10 \mathrm{~Hz}$. The output of the YAG laser was split three ways. Approximately $80 \mathrm{~mJ}$ was used as the green pump beam for CARS. A homemade, conventional axially-pumped broadband dye laser operating at $607 \mathrm{~nm}$ was pumped using $250 \mathrm{~mJ}$ of green light from the doubled Nd:YAG. The dye solution consisted of Rhodamine 640 laser dye in methanol. The line shape of the broadband laser was represented by the sum of two Gaussian distributions, the main Gaussian having a width of approximately $130 \mathrm{~cm}^{-1}$. The second Gaussian was approximately $10 \%$ of the main Gaussian in amplitude, but several times more broad. This second curve was necessary to ensure proper normalization to the nonresonant CARS signal in the wings of the spectrum, particularly since the CARS spectrum can include strong $\mathrm{H}_{2}$ lines near the edge of the profile. Additional details about the above components of the laser system can be found in Ref. 6.

Another $200 \mathrm{~mJ}$ of 532-nm light was used to pump a yellow (554-nm) narrowband dye laser (Lambda Physik, FL3002), discussed in detail in Ref. 12. The green and red beams were combined using a dichroic mirror. These two beams plus the yellow beam were then passed through a spherical lens having a focal length of $410 \mathrm{~mm}$. The Planar BoxCARS phase-matching geometry was used, with the green and red beams overlapping. The probing volume formed at the intersection of the three beams had a minimum diameter of $130 \mu \mathrm{m}$, full-width at half-maximum (FWHM), measured by traversing a knife-edge across the foci of all three beams. The probe volume is $1.8 \mathrm{~mm}$ long FWHM, as measured by traversing the probe volume across a thin planar jet of nitrogen gas, surrounded by a 30mm-diameter jet of argon, and measuring the $\mathrm{N}_{2}$ CARS signal as the probing volume was traversed across the nitrogen sheet.

A second 410-mm focal-length lens collected and collimated the three input beams and the 491-nm CARS signal beam. Two dichroic mirrors that efficiently reflected blue while transmitting yellow and green light were arranged in a multi-reflection configuration to isolate the blue signal beam. This blue beam was then directed into a one-meter spectrometer (McPherson) with a 1200 groove/mm grating. Two cylindrical lenses provided a sharp horizontal focus at the spectrometer entrance that was reimaged, spectrally dispersed, at the detector. The detector was an 1100x330-pixel, non-intensified, back-illuminated, CCD camera (Pixel Vision, SV11CBJ). A LabView interface downloaded the spectra to a PC for subsequent analysis and could display spectra in real time for signal optimization. The 330-pixel region was binned into three separate rows of 110 pixels before being read out, to allow more rapid acquisition of data. This resulted in three 1100-pixel spectra per laser pulse, with a spectral resolution of $0.74 \mathrm{~cm}^{-1}$ per pixel. The CARS signal was imaged onto the first two of these regions, with the contributions of dark noise and laser scatter acquired on the third bin region. Distributing the signal over two bin regions increased the dynamic range of the measurements by up to a factor of two. The binned background was subtracted from each of the signal bin regions before the signal regions were summed to form the total spectrum.

The spectral non-uniformity of the Stokes laser was accounted for by normalizing the CARS signal to an averaged non-resonant CARS signal obtained immediately after completion of the day's runs. The profile of the broadband laser was measured by obtaining nonresonant CARS spectra in a flow of argon, averaged over 200 laser pulses. A sum of two Gaussian functions was fitted to the broadband laser profile, as mentioned above. Each of the image acquisitions was normalized using this fitted profile. 


\section{CARS Spectral Data Analysis}

A full description of the CARS spectral analysis methods for flow temperature and molecular species determination can be found in Ref. 12. A brief summary of these analysis methods is provided below.

In the current CARS system configuration the broad band Stokes laser spectrum varies during the day due to alignment and temperature variations. This spectral variation must be measured and accounted for during data analysis, as detailed in Ref. 12. Measured resonant CARS spectra are typically spectrally broader than theoretical spectra, mainly owing to the low-resolution dispersion of the spectrometer. The shape and width of this broadening, known as the "instrument function", was inferred by fitting an instrument function to a room-air CARS spectrum obtained prior to the day's experiments. The fitted instrument function was used to generate the theoretical spectra for that day's runs. We used the CARSFIT code ${ }^{15}$, developed at Sandia National Laboratories, Livermore, CA, and subsequently modified by Hancock et al. ${ }^{11}$ to compute the theoretical dual-pump CARS spectra. In order to quickly fit the many thousands of CARS spectra obtained in the experiment, CARSFIT was used to determine a 4dimensional (temperature, $\mathrm{N}_{2}, \mathrm{O}_{2}$, and $\mathrm{H}_{2}$ mole fractions) library of spectra, using the Voigt profile to model the individual Raman transition strengths and assuming that the only other gas present was $\mathrm{H}_{2} \mathrm{O}$. The original dualpump CARSFIT code was modified to include convolutions with both pump beams and the instrument function ${ }^{12}$ as the original version of the code ${ }^{11}$ assumed a monochromatic pump beam. The Nd:YAG laser used in these experiments was not injection-seeded, so the laser line width is large compared to the line width of the individual Raman transitions. An error in the adaptive grid calculation for $\mathrm{H}_{2}$ transitions was also removed from the code, allowing the faster adaptive grid calculation to be used for $\mathrm{H}_{2}$ spectrum calculations.

The library of theoretical CARS spectra contains temperature intervals of $200 \mathrm{~K}$ and between 10 and 12 mole fraction values, depending upon the species. Oxygen mole fractions are included between 0 and 0.4 , while the $\mathrm{N}_{2}$ and $\mathrm{H}_{2}$ mole fractions vary between 0 and 1 . Mole fraction values are more closely spaced near zero, in order to achieve better resolution at low molar concentrations. An initial guess of temperature and composition is obtained by comparing each single-shot measured spectrum to every theoretical spectrum in this coarse library to find a best fit. A more precise estimate of temperature and composition is then obtained using "theoretical" spectra linearly interpolated between the library entries: the absolute deviation between these theoretical spectra and the measured spectrum was minimized using a nonlinear least-squares method. Errors caused by this interpolation scheme were far smaller than other random errors in the experimental data: a set of test spectra generated by CARSFIT having been fit with average temperature errors of $2.1 \mathrm{~K}$ and mole fraction errors of less than $0.003 .{ }^{12}$

\section{Prior CARS Calibration Experiments}

The CARS system was characterized by making measurements in an atmospheric-pressure furnace and an atmospheric-pressure laminar flat-flame burner. ${ }^{8,16}$ Average values of temperature and mole fraction were determined from single-acquisition measurements. Mean temperature measurements in a furnace containing air between 300 and $1800 \mathrm{~K}$ agreed with thermocouple measurements within $26 \mathrm{~K}$ on average, while mean mole fractions agreed to within $1.6 \%$ of the nominal value for atmospheric air. The temperature measurement standard deviation averaged $64 \mathrm{~K}$ while the standard deviation of the species mole fractions averaged $7.8 \%$ for $\mathrm{O}_{2}$ and $3.8 \%$ of the measured value for $\mathrm{N}_{2}$, based on 200 single-shot measurements. The measurements in an $\mathrm{H}_{2}$-air laminar flatflame Hencken burner for fuel-lean and fuel-rich conditions are presented in detail in Ref. 8.

Measured $\mathrm{H}_{2}$ mole fractions were systematically low by $10-15 \%$ when compared to the computation. This corresponds to a systematic difference of more than one standard deviation in the measurement for fuel-rich flame conditions. The most likely cause for this discrepancy is inaccurate modeling of the $\mathrm{H}_{2}$ spectroscopy in the CARSFIT code. This systematic $\mathrm{H}_{2}$ error may be caused by the line-shape model used to calculate the spectra. The Voigt profile was used to calculate transition widths for all species. This profile function does not account for Dicke narrowing ${ }^{17}$ caused by velocity-changing collisions that conserve the vibrational phase of the molecule. This effect becomes more significant as the pressure of the flow increases, and is larger for interactions involving $\mathrm{H}_{2}$ than for other molecules because the strength of the effect is related to the diffusion rate of the molecule. Further studies are required, over a range of controlled conditions, in which the composition and temperature can be varied over a wide range of values. Consequently, at present, the $\mathrm{H}_{2}$ mole fraction measurement should be considered qualitative.

\section{MDOE and Response Surface Methods}

The experimental data were obtained using a formal experiment design method, known as Modern Design of Experiments (MDOE). This method is detailed in References 18 and 19 and briefly summarized here. The CARS probe volume was scanned through the flowfield along horizontal and vertical lines - one scanned line per tunnel run. The order and direction of these scans was randomized to defend against systematic errors caused by factors like heating of the duct during a facility run. Repeat measurements (measurements made in a fixed location repeatedly) were obtained to improve measurement uncertainty and to provide a quantitative determination of the uncertainty and repeatability of the measurement system and flow facility. 
After the CARS spectra were processed to determine the temperature and the mole fractions at various locations in the duct, response surfaces were fit to these data to provide quantitative maps of the mean flowfield parameters. These maps provide a visual representation for interpretation of the results. A sequential fitting method using the Saturated Gaussian function and the Cosine Series Bivariate Order 6 (CSBO6) function was used to fit the temperature and mole fraction data as well as the correlations between fluctuating properties. The CSBO6 function was chosen because of its ability to fit the majority of the data sets with statistically high fidelity. A "Saturated Gaussian" function was included in the fit to better represent the sharp features present in some of the data. The inability to fit sharp features in the data sets was one of the major limitations of the MDOE method identified in previous work. ${ }^{12}$ This function, inspired by a saturated absorption spectrum, is given by:

$$
f(x, y)=a-b\left(1-e^{\left.-c e^{-\left(\left(\frac{x-d}{f}\right)^{2}+\left(\frac{y-g}{h}\right)^{2}\right)}\right)}\right)
$$

where $\mathrm{a}, \mathrm{b}, \mathrm{c}, \mathrm{d}, \mathrm{f}, \mathrm{g}$, and $\mathrm{h}$ are free parameters (usually positive valued) and e is the base of natural logarithms.

Each plane of measured data was fit with the sum of this Saturated Gaussian and the CSBO6 function. Unfortunately, when fitting to this combined function, the fitting algorithm was not robust enough to produce the optimal fit to the data each time. It was often found that the choice of initial guess could improve the chi-squared error upon termination of the fit. Since these errors were substantially reduced compared to fitting with the CSBO6 only, an alternate fitting strategy was adopted. The sequential fitting method was performed by first fitting the data set with a Saturated Gaussian function. Then this Saturated Gaussian surface was subtracted from the data and the difference was fit with the CSBO6 function. This sequence is repeated 25-100 times with different Saturated Gaussian surfaces (chosen by inspection) until a minimum fit error is reached, with consideration paid to the other fit statistics. While this method can return better fitting statistics than the CSBO6 function alone it does not guarantee the best statistical solution since the process is nonlinear, operator dependent, and a robust algorithm has not yet been written. Sometimes the sequential method did not improve the statistics of the CSBO6 function fit for a data set. This typically occurs when no sharp features are present in the data set. These cases have been fitted with the CSBO6 function only.

Regardless whether the sequential method is used, the terms with coefficients that are statistically insignificant are removed from the fit. The significance is determined by whether the statistical P-value for the term is greater than 5 percent and is therefore considered by statistical fitting standards as found by chance. ${ }^{20}$ This removes terms that did not improve the quality of the fit thereby improving the confidence in the remaining parameters. Consequently, the confidence interval half-width $(C I H W)$ uncertainty, which depends on the number of parameters in the fit equation, also reduces. In other words removing terms removes uncertainty added by terms that did not add significantly to the fidelity of the fit. These surface fits, by virtue of their limited number of fit coefficients (much less than the number of data points), smooth (or average) the data.

Using these fitted surfaces to determine mean values of the flowfield parameters one can then compute statistics of the fluctuations in the measured parameters. ${ }^{19}$ The difference between each measured sample and the mean, denoted by a primed quantity such as $T^{\prime}$ for temperature fluctuations and $\chi_{i}^{\prime}$ for fluctuations of species $i$, and the chosen fluctuation product, such as $T^{\prime} T^{\prime}$, is found. The fluctuation product data are then fit to a response surface, as described above, to provide an estimation of the distribution of mean values of the product. In this way, the temperature fluctuation variance, $\left\langle T^{\prime} T^{\prime}\right\rangle$, which is related to root-mean square (RMS) temperature fluctuations, $\left(<T^{\prime} T^{\prime}>\right)^{1 / 2}$, can be computed. Similarly, covariances, such as $\left\langle T^{\prime} \chi_{\mathrm{H} 2}{ }^{\prime}>\right.$ are also calculable.

\section{CARS Results}

\section{A. Combustor Measurements: Single-Shot Results}

Figure 2 shows several representative CARS spectra measured in the combustor. The experimental data, the best theoretical fit and the residual (difference between the fit and the data) are shown in each graph. These spectra show the quality of fits to the data for planes 3 and 6 , at a variety of flow conditions characteristic of (a) the freestream conditions, (b) hot gas containing mostly $\mathrm{H}_{2}$ and $\mathrm{N}_{2}$, (c) cool flow outside the duct in the window space (mostly air) and (d) flow in the unburnt fuel jet containing $\mathrm{H}_{2}, \mathrm{~N}_{2}$ and $\mathrm{O}_{2}$. Spectra containing all three species simultaneously are rare, as temperatures that are high enough to show significant $\mathrm{H}_{2}$ signal are likely to cause combustion to occur. 
(a)

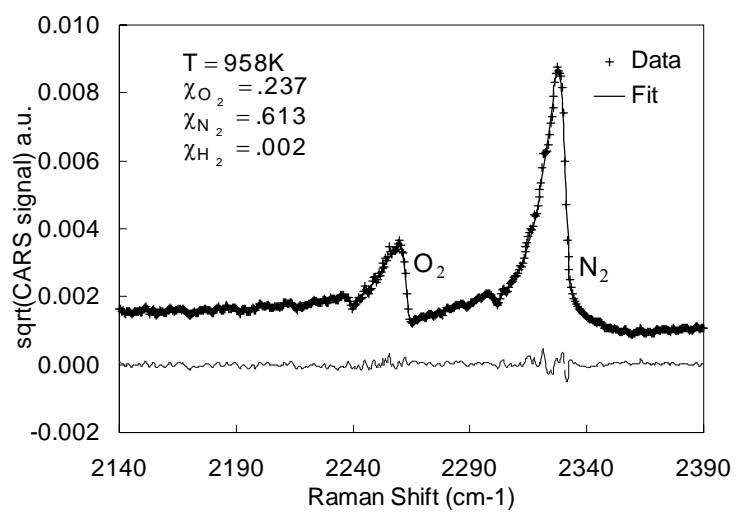

(c)

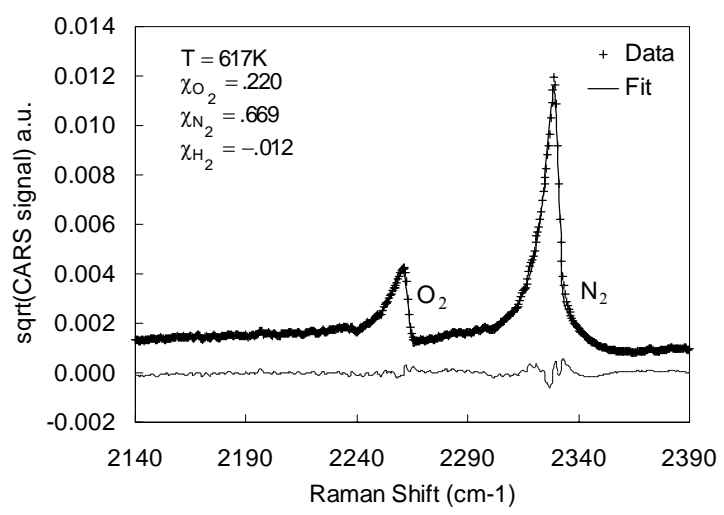

(b)

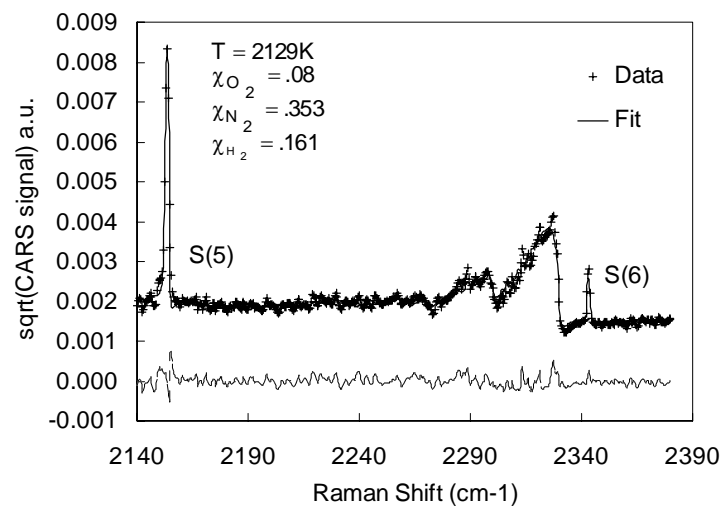

(d)

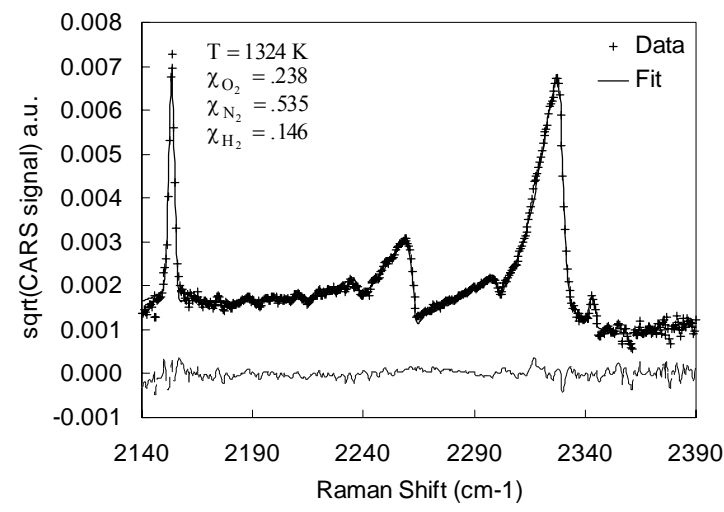

Figure 2. Sample CARS spectra from planes 3 and 6. The $\mathrm{N}_{2}$ and $\mathrm{O}_{2} \mathrm{Q}$-branch spectra are labeled, as are the pure rotational $\mathrm{S}(5)$ and $\mathrm{S}(6)$ transitions of $\mathrm{H}_{2}$.

Figure 3 offers some insight towards understanding the systematic error in the fit of the $\mathrm{H}_{2}$ seen in approximately a quarter of the data set. These fits using the Voigt Profile line shape model do not correctly model the width of the $\mathrm{H}_{2}$ lines. This poor fit to the $\mathrm{H}_{2}$ is apparent in the highest-pressure planes 3 and 6 and as mention previously, may be caused by Dicke narrowing. Figure 3(c) demonstrates another example of the error in the fit to $\mathrm{H}_{2}$. For plane 6 the instrument function is determined using a shot that includes $\mathrm{H}_{2}$. The resulting instrument function has widths that are between the width of the $\mathrm{H}_{2}$ and $\mathrm{N}_{2}$, possibly causing an error in determining the temperature from the $\mathrm{N}_{2}$ spectrum. A possible remedy to avoid this compromise of widths is to fit the instrument function with a shot containing no $\mathrm{H}_{2}$ thus avoiding the affect of the compromise of widths. Such a remedy was utilized in plane 3 and while this corrects the fit of the $\mathrm{N}_{2}$ band (probably resulting in a more accurate temperature) the width of the $\mathrm{H}_{2}$ is no longer adequately fit with this instrument function as shown in Fig. 3(a). Since the narrow width of the $\mathrm{H}_{2}$ cannot be fully modeled without accounting for Dicke narrowing, $\mathrm{H}_{2}$ mole fraction surface fits can only be considered qualitative in the present experiment. The ability to more accurately fit for $\mathrm{N}_{2}$ (and consequently temperature) is more desirable than the qualitative fit of $\mathrm{H}_{2}$. Therefore this remedy is planned for a refit of plane 6 to ensure accurate temperatures and $\mathrm{N}_{2}$ mole fractions. 
(a)

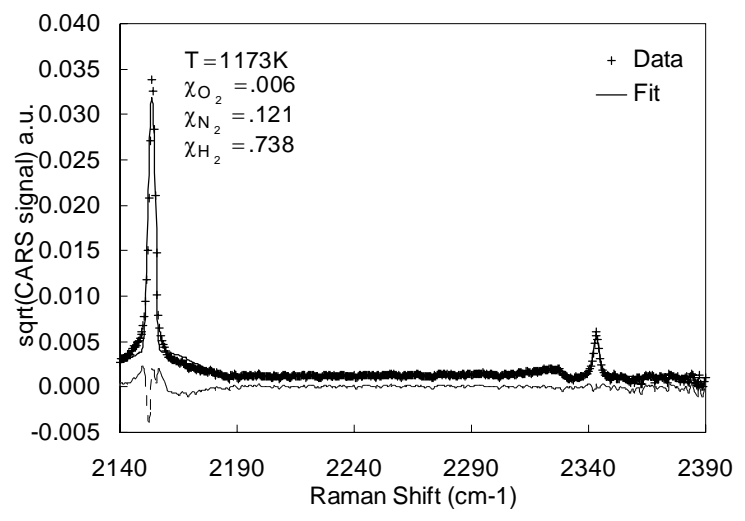

(b)

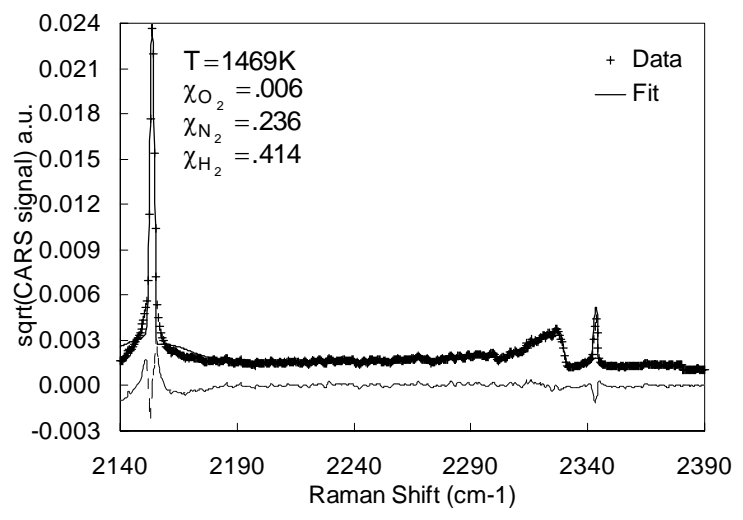

(c)

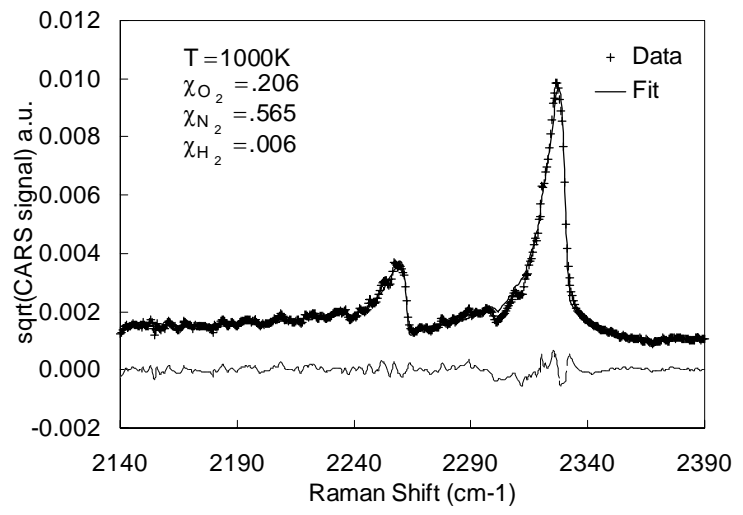

Figure 3. Sample CARS spectra of poor fits of mainly $\mathrm{H}_{2}$ (a) from plane 3 and (b) from plane 6 and of $\mathrm{N}_{2}$ (c) from plane 6 . (a)

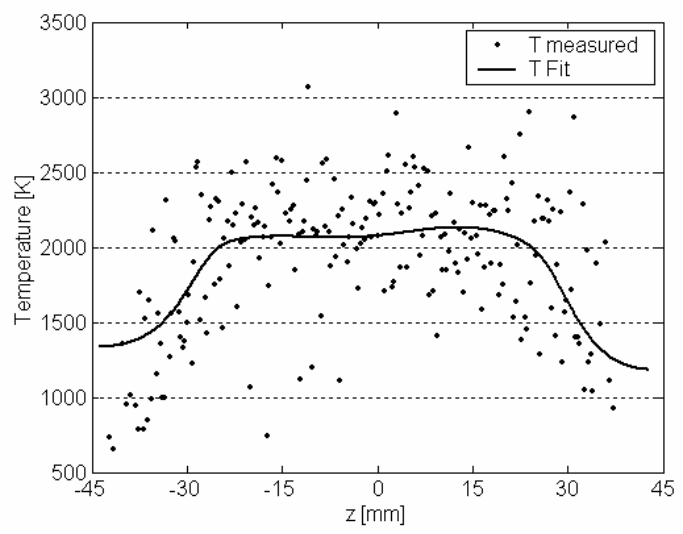

(b)

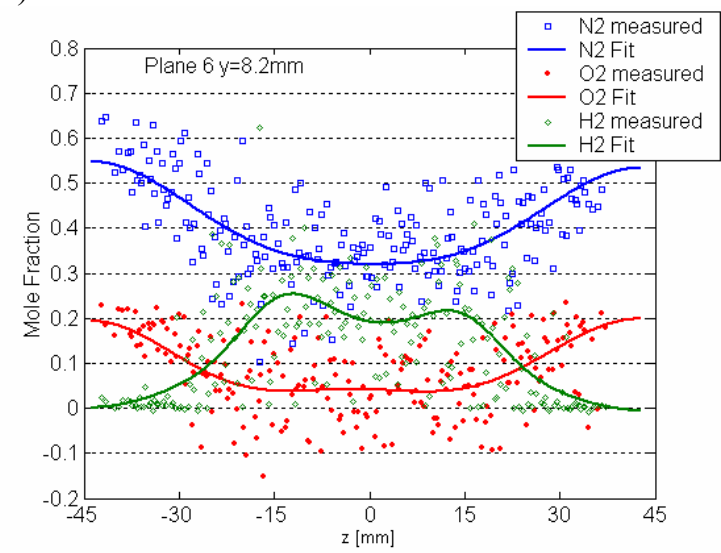

Figure 4. (a) Temperature and (b) mole fraction plots for a horizontal facility run in plane 6 at $y=8.2 \mathrm{~mm}$, showing the measurement data (points) and the surface fit (lines).

Figure 4 shows a set of measurements for a single tunnel run in which the interaction region was scanned horizontally across the duct at plane 6 and at $y=8.2 \mathrm{~mm}$. The coordinate system is chosen such that its origin is in the center of the nozzle exit plane, with the bottom wall of the duct at $y=-19.3 \mathrm{~mm}$. The plot shows the scatter of the temperature and mole fraction measurements during the traverse. Most of this scatter, particularly in the hightemperature portion of the plot, is due to turbulence rather than random errors of the measurement technique: the random error of the CARS system (determined in calibration experiments, described in Section V) is significantly smaller then the variations seen in the traverse. 


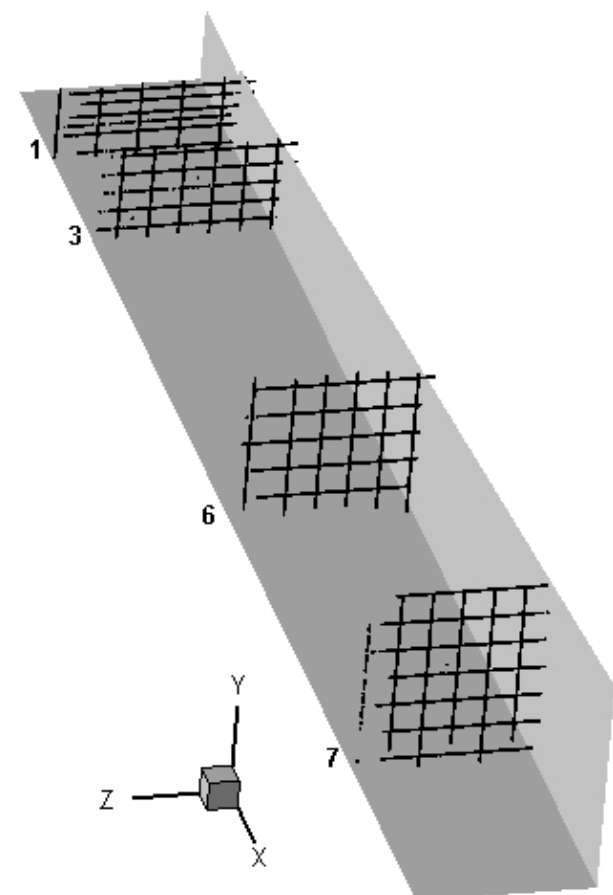

Figure 5. Plot showing the measurement locations for each of planes 1, 3, 6 and 7 .

\section{B. Mean Flow Parameter Maps in the Combustor}

The CARS measurement plane locations are shown in Fig. 5. Each measurement plane was comprised of a "grid" of 1500 - 2000 discrete measurement locations, arranged in rows and columns within the measurement plane. Data along the grid columns were obtained by traversing the CARS system spanwise during a run, whereas data along the grid columns were obtained by traversing the CARS system vertically during a run. All measurements within a particular measurement plane were obtained on the same day. Additional measurements were obtained to assess measurement and flow repeatability. These additional measurements included repeat scans along a given line within a measurement plane, and repeat measurements at a single location within the flow throughout a run.

Figures 6 and 7 summarize the distributions of mean temperature and species concentration, measured by the CARS system and fitted with the response surfaces determined by the sequential fitting method described previously. Figure 6 shows the vectored fuel injection from Ref. 8 and Figure 7 are results from the current normal-fuel injection test. The following discussion will concentrate on the results in Figure 7 and use the results from Figure 6 for comparison. Note that Figure 6 looks slightly different than the corresponding figure reported in Ref. 8. Some minor errors were identified and corrected in this data set. Furthermore, both the sequential method of fitting response surfaces and the removal of insignificant terms in the response surfaces, described above, were used to re-process this data, resulting in better fit statistics.

Table 1 shows predicted and measured freestream conditions in plane 1 for both fuel injection cases. The measured properties presented are the average across the duct between $z= \pm 40 \mathrm{~mm}$. These measurements are in reasonable agreement with calculated values, falling within the standard deviation of the measurements, but not within the $95 \%$ confidence fit uncertainties for the plane. Another method of determining the variability of the freestream conditions involves maintaining the laser at a single location over a run. Such a run for the normal fuel injection case was obtained in plane 1 at the location $(4 \mathrm{~mm}, 0.2 \mathrm{~mm})$ over 159 spectrum acquisitions. This location was near the middle of the duct. The mean flowfield properties over this run are $T=1020 \mathrm{~K}, \chi_{\mathrm{O} 2}=0.233$, $\chi_{\mathrm{N} 2}=0.607$ and $\chi_{\mathrm{H} 2}=0.002$ with standard deviations of $103 \mathrm{~K}, 0.024,0.037$ and 0.007 respectively. Although the properties of this run do not agree with the properties measured by averaging across the duct, valuable information is gained from this measurement. The fact that that the standard deviation for the temperature measured across the duct and that measured at a single location are both larger than the $70 \mathrm{~K}$ standard deviation measured from the laminar flame indicates that the variations in the temperature are large enough to be resolved by the CARS system.

\begin{tabular}{|cc|c|c|c|c|}
\hline & & $\mathrm{T}(\mathrm{K})$ & $\chi_{\mathrm{O} 2}$ & $\chi_{\mathrm{N} 2}$ & $\chi_{\mathrm{H} 2}$ \\
\hline $\begin{array}{c}\text { Vectored Fuel } \\
\text { Injection }\end{array}$ & Predicted & $1185 \pm 60$ & 0.187 & 0.513 & 0 \\
\hline $\begin{array}{c}\text { Normal Fuel } \\
\text { Injection }\end{array}$ & Preasured & $1250 \pm 151$ & $0.204 \pm .024$ & $0.494 \pm .042$ & $0.003 \pm .009$ \\
\hline
\end{tabular}

Table 1. Plane 1 freestream conditions at nozzle exit values quoted are mean values \pm 1 standard deviation.
Another interesting outcome of the plane 1 measurements (Fig. 7) is the nonuniform distribution of both $\mathrm{O}_{2}$ and, to a lesser extent on a percentage basis, $\mathrm{N}_{2}$ mole fraction. For both species, mole fraction is increasing to the right of the plane. This is not an artifact of the heating of the facility during each run, because care was taken to traverse the duct in both positive and negative $z-$ directions to prevent such systematic errors. Similar asymmetries can also be seen near the edges of planes 6 and 7 , and always occur in the direction of increasing from left to right across the plane. This same nonuniform distribution can be seen in Fig. 6 for the vectored fuel injection case. The temperatures in both cases show a relatively uniform distribution. The mole fraction asymmetry indicates an asymmetry in the replenished $\mathrm{O}_{2}$ in the freestream flow, and the lack of $\mathrm{H}_{2}$ detected in the freestream indicates that full combustion of the vitiate has occurred. In the normal injection experiments, the $\mathrm{O}_{2}$ content of the freestream is slightly higher than predicted. This illustrates the importance of being able to measure mole fraction in combusting flows, in addition to temperature: such a variation in inlet conditions is likely to impact the location and extent of combustion further downstream, and a computation that assumes constant mole fraction across the duct would be unlikely to reproduce the measured temperature distribution. 

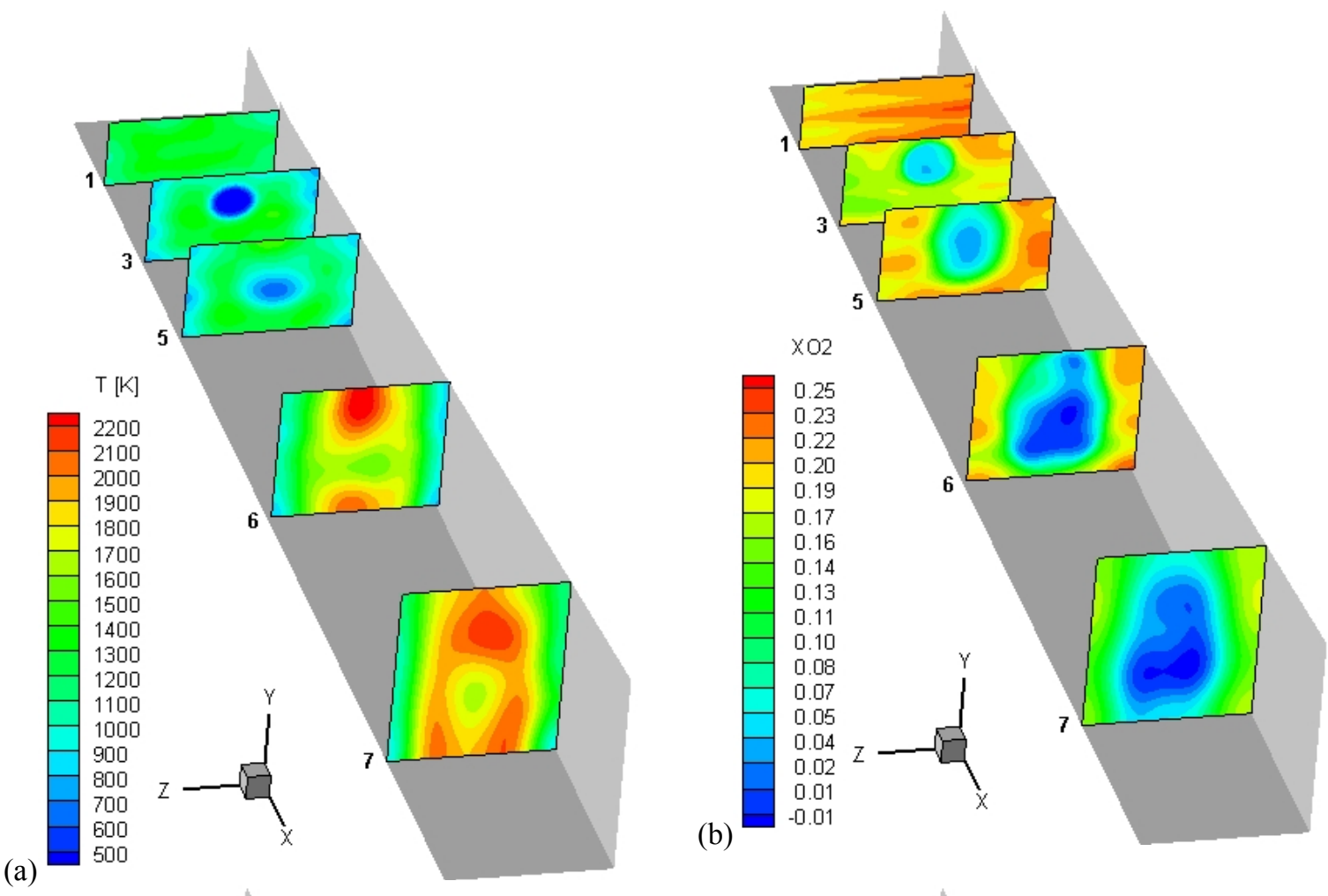

(a)
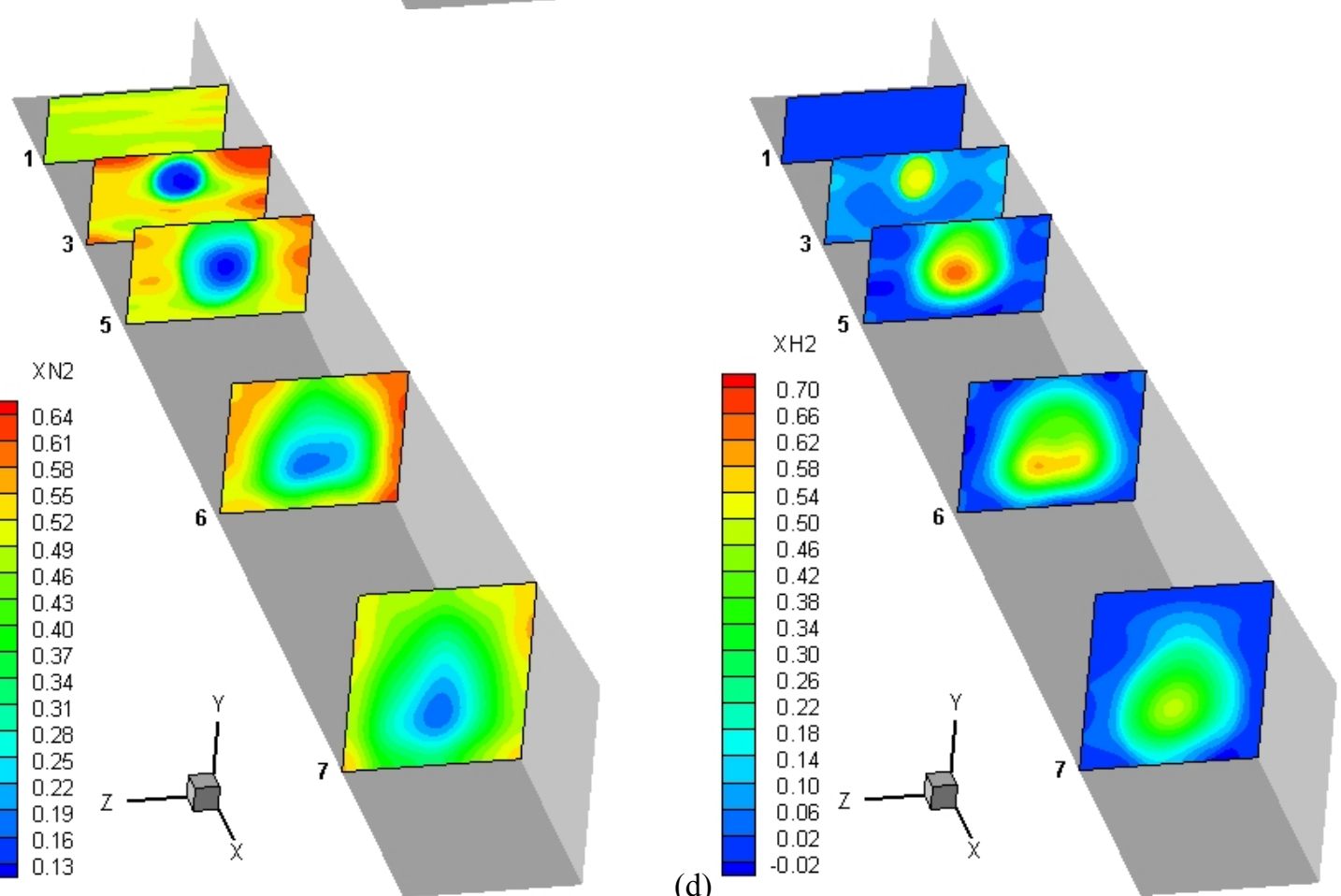

(c)

Figure 6. Plots of (a) mean temperature (b) mean $\mathrm{O}_{2}$ mole fraction, (c) mean $\mathrm{N}_{2}$ mole fraction, (d) mean $\mathrm{H}_{2}$ mole fraction at Mach 7 enthalpy for the vectored-fuel-injection case (Ref. 8). 

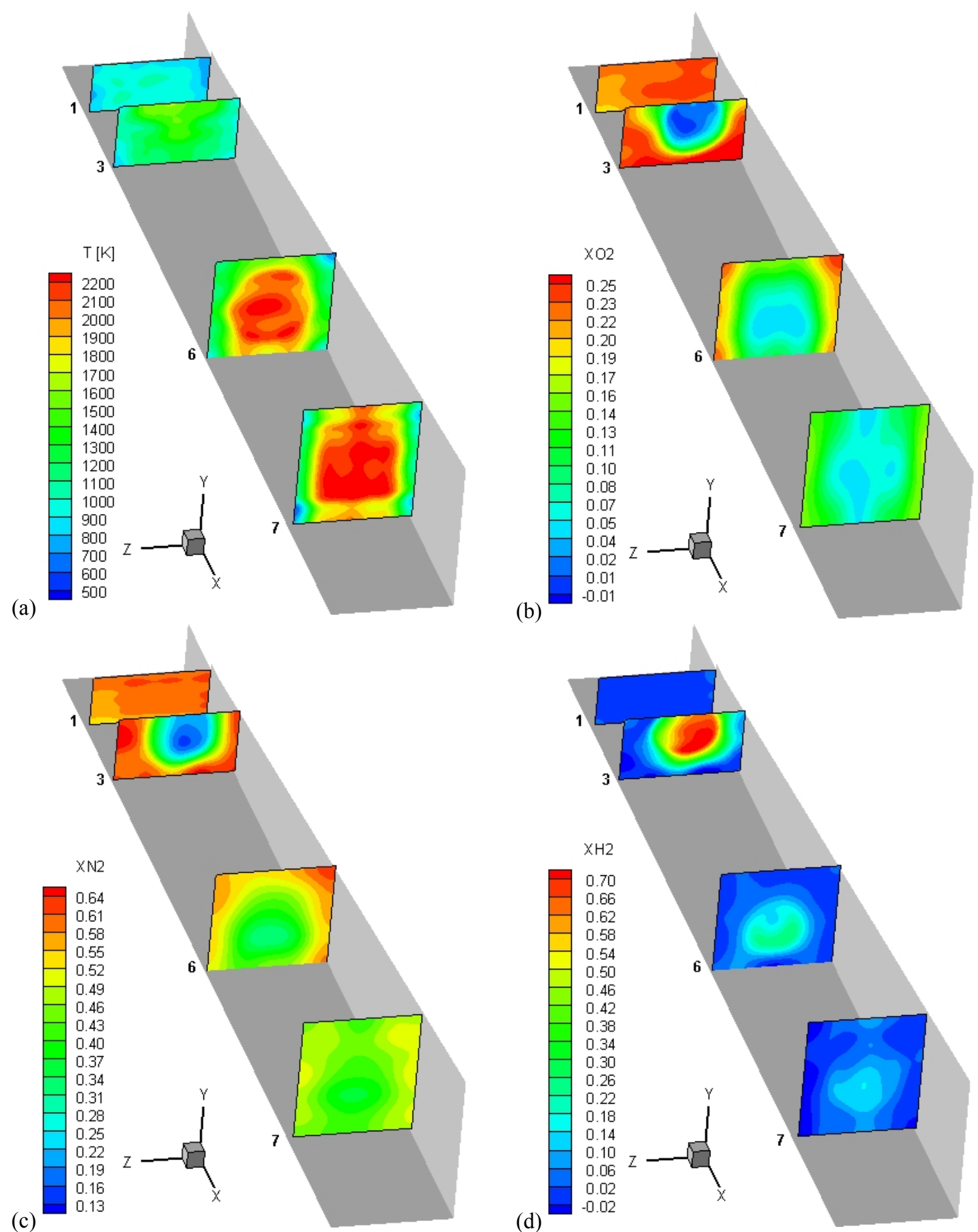

Figure 7. Plots of (a) mean temperature (b) mean $\mathrm{O}_{2}$ mole fraction, (c) mean $\mathrm{N}_{2}$ mole fraction, (d) mean $\mathrm{H}_{2}$ mole fraction at Mach 6 enthalpy for the normal fuel injection case. 


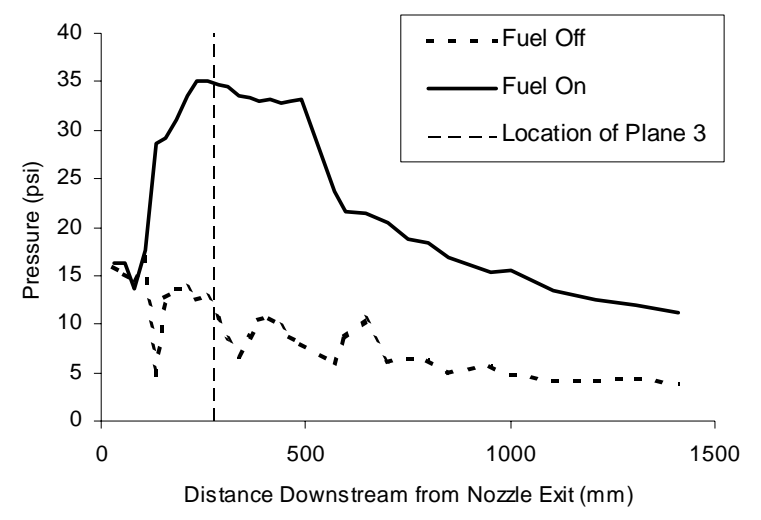

Figure 8. Pressure profile along the bottom wall of the combustor.

as seen in Figure 6, significant combustion for the vectored-fuel-injection case does, injection case doesn't occur until after plane 5. It is likely that the subsonic region of flow generated by the normal fuel injection acts as a flame holder, whereas the supersonic vectored injection does not hold flame in this manner. The stronger bow shock generated by the normal injection will also increase the temperature of the flow compared to the vectored-injection case, reducing the ignition delay time

Comparison of the mean $\mathrm{O}_{2}$ distributions in Figures 6 and 7 shows that, in the vectored-injection case, the $\mathrm{O}_{2}$ in the central part of the duct was fully consumed by the time the flow had reached plane 7 , whereas excess $\mathrm{O}_{2}$ was still noticeable at plane 7 for the normal-injection tests. This result is consistent with the conditions being stoichiometric for the vectored-injection tests and fuel-lean for the normal-injection experiments. Another possible explanation of the depletion of $\mathrm{O}_{2}$ in the center of the duct is the effect on mixing of the direction of the fuel injection. The direction of injection relative to the freestream gas in the vectored-injection case causes less shear forces than the normal-injection case and therefore less mixing is initiated at injection than in the normal-fuel-injection case. The fuel jet is not mixed as completely as in the vectored case and this more concentrated jet is maintained in all planes preventing $\mathrm{O}_{2}$ from penetrating into the middle of the duct.

Once the flow reaches plane $6, \mathrm{~N}_{2}$ is somewhat uniform across the plane indicating that air has penetrated to the center of the fuel jet. However, consumption of $\mathrm{O}_{2}$ continues to produce an $\mathrm{O}_{2}$ deficit near the center of the fuel jet. In this same location, temperature has risen above $2000 \mathrm{~K}$. In comparison with the vectored case at plane 6 , the temperature at the center of the fuel jet is only $\sim 1500 \mathrm{~K}$ and the $\mathrm{O}_{2}$ mole fraction is approximately zero at the center of the $\mathrm{H}_{2}$ plume. This is further evidence that the gases appear to be mixing more completely in the normalinjection case. In the vectored case there is more $\mathrm{H}_{2}$ present in plane 6 than for the normal case because of the poorer mixing and later start of combustion.

In plane 7 of the normal injection case (Fig. 7) only a small amount of $\mathrm{H}_{2}$ remains and the $\mathrm{N}_{2}$ is almost completely uniform. By contrast, the vectored case shows relatively more $\mathrm{H}_{2}$ in plane 7 indicating less mixing of the gasses within the duct. However, one should further keep in mind that the equivalence ratio for the normal injection case was 0.7 whereas it was 1.0 for the vectored injection case. This fact could explain some of the differences observed in the distributions.

Table 2 summarizes the uncertainty in the fits in these mean quantities. These values represent the $95 \%$ confidence interval half-width $\left(C I H W_{95 \%}\right)$, i.e., the uncertainty in the fit's prediction of the mean surface. The quoted uncertainty is the average over the entire surface of a given plane. With the exception of $\mathrm{H}_{2}$, these mean property maps exhibit statistical uncertainties that are typically twice as big as the systematic errors discovered during the flame and furnace calibration studies. For example, typical temperature measurement fit uncertainties were 60-70 K, whereas systematic errors were on the order of 25-30 K. Similarly, the statistical fit uncertainties for $\mathrm{N}_{2}$ and $\mathrm{O}_{2}$ mole fraction were typically between 0.01 and 0.02 , whereas the systematic errors were 0.01 or lower. These results indicate that acquiring a factor of 2 or 3 times more data per plane would have been a sensible investment of resources to reduce these random errors to the same level as the systematic errors. However, acquiring more than 4 times more data would reduce the statistical errors to a level lower than the systematic errors, which would probably be a poor use of resources. 


\begin{tabular}{|c|c|c|c|c|c|c|c|c|c|c|c|c|}
\hline \multirow{2}{*}{$\frac{\text { Parameter }}{\mathrm{T}}$} & \multicolumn{3}{|c|}{\begin{tabular}{|c|} 
Plane 1 \\
CIHW $_{95 \%}$ Mod. F LOF P \\
\end{tabular}} & \multicolumn{3}{|c|}{\begin{tabular}{|c} 
Plane 3 \\
CIHW $_{95 \%}$ Mod. F LOF P \\
\end{tabular}} & \multicolumn{3}{|c|}{\begin{tabular}{|c} 
Plane 6 \\
CIHW $_{95 \%}$ Mod. F LOF P \\
\end{tabular}} & \multicolumn{3}{|c|}{\begin{tabular}{|c|} 
Plane 7 \\
CIHW $_{95 \%}$ Mod. F LOF P \\
\end{tabular}} \\
\hline & 20 & $\mathrm{P}$ & $\mathrm{P}$ & 56 & $\mathrm{P}$ & $\mathrm{P}$ & 76 & $\mathrm{P}$ & $\mathrm{P}$ & 59 & $\mathrm{P}$ & $\mathrm{P}$ \\
\hline$\chi_{\mathrm{N}_{2}}$ & 0.007 & $P$ & $\mathrm{P}$ & 0.022 & $P$ & $\mathrm{~F}$ & 0.013 & $\mathrm{P}$ & P & 0.009 & P & $P$ \\
\hline$\chi_{\mathrm{O}_{2}}$ & 0.003 & $\mathrm{P}$ & $\mathrm{P}$ & 0.012 & $P$ & F & 0.011 & $\mathrm{P}$ & $\mathrm{P}$ & 0.007 & $\mathrm{P}$ & $\mathrm{P}$ \\
\hline$\chi_{\mathrm{H}_{2}}$ & 0.002 & P & $\mathrm{F}$ & 0.037 & P & F & 0.016 & $\mathrm{P}$ & $\mathrm{P}$ & 0.013 & P & $\mathrm{P}$ \\
\hline
\end{tabular}

Table 2. Statistical $95 \%$ confidence interval half width uncertainties $\left(\mathrm{CIHW}_{95 \%}\right)$ in fitted surfaces, and results of the Model F-statistic (Mod. F) and Lack of Fit P-statistic (LOF-P) tests. "P" and "F" indicate pass and fail, respectively. Note that statistical uncertainties do not account for systematic errors in measured quantities.

test. Choosing a completely different functional form might have allowed a better fit that would pass this test. However this was not done because it was desired to use the same fitting functions for all of the surfaces, to avoid introducing another variable into the analysis. It is also likely that acquiring more data would have allowed these statistics to be satisfied, as both Model F and Lack of Fit P-statistics improve with increased data volume.

(a)

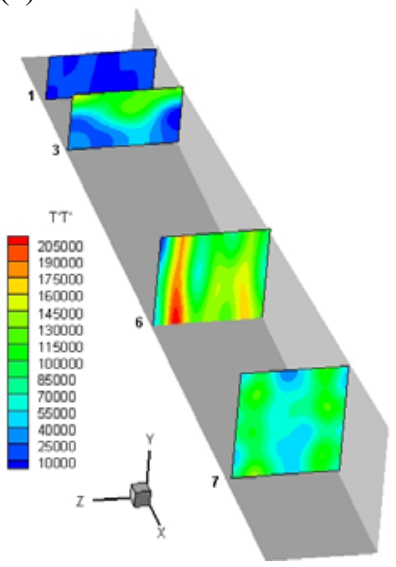

(b)

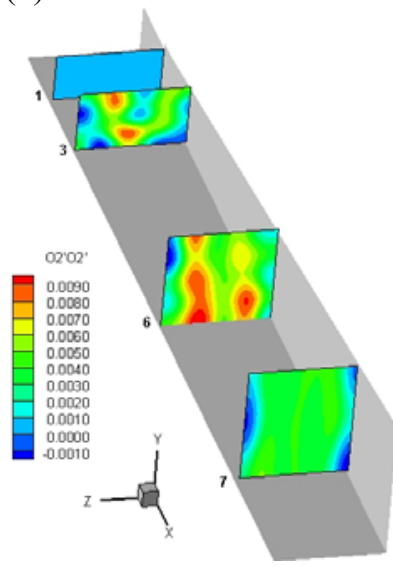

(c)

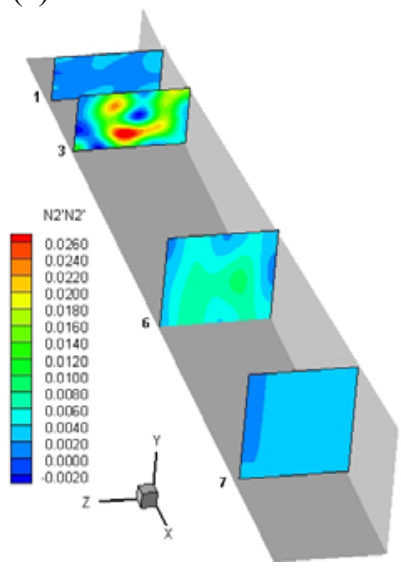

(d)

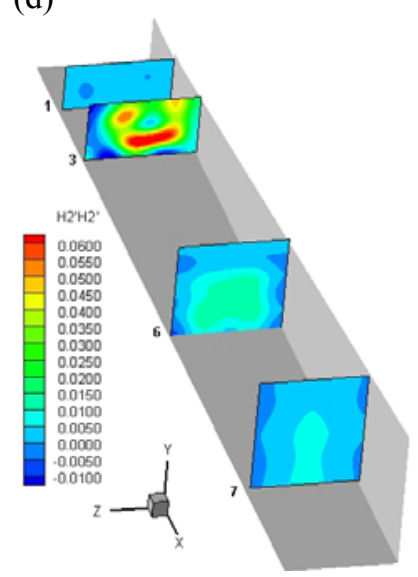

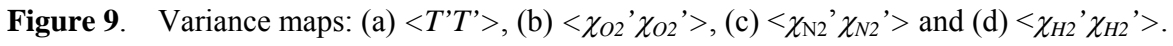

\section{Spatial Variation of Correlations in Fluctuating Parameters}

As mentioned in the introduction, one of the main benefits of dual-pump CARS as a measurement technique is that it allows more than one flow property to be measured simultaneously. This capability allows us to determine correlations between each of the measured flow properties in the duct, as a function of position. Such information is useful in the development of turbulence models for CFD simulations, and also provides important qualitative information about mixing in this particular combustor.

We classify the correlations into three categories: variances, such as $\left\langle T^{\prime} T^{\prime}\right\rangle,\left\langle\chi_{\mathrm{O} 2}{ }^{\prime} \chi_{\mathrm{O} 2}{ }^{\prime}\right\rangle$, and $\left\langle\chi_{\mathrm{N} 2}{ }^{\prime} \chi_{\mathrm{N} 2}{ }^{\prime}\right\rangle$, covariances between the various mole fractions, such as $\left\langle\chi_{\mathrm{N}_{2}}{ }^{\prime} \chi_{02}{ }^{\prime}\right\rangle$, and covariances between the temperature and various mole-fractions, such as $\left\langle T^{\prime} \chi_{\mathrm{N} 2}^{\prime}\right\rangle$ and $\left\langle T^{\prime} \chi_{\mathrm{O} 2}{ }^{\prime}\right\rangle$.

The variance maps are presented in Fig. 9. In plane 3, all of the variances of mole fraction have regions of low fluctuation at the edges of the plot, where the gas is mostly freestream, and in the center of the plot, where much of the flow is $\mathrm{H}_{2}$ from the fuel jet. Between these two regions, all four maps show regions of large fluctuations, particularly along the sides of the fuel plume. Significant fluctuations are present at the top of the duct in the $\left\langle T^{\prime} T^{\prime}\right\rangle$ map indicating that the combustion is initiated near plane 3 from the upper regions of the flowfield, despite the fact that the mean temperature is uniform across the duct.

Comparing the mole fraction variance maps in Fig. 9 (b), (c) and (d) shows that the $\mathrm{N}_{2}$ and $\mathrm{H}_{2}$ distributions look more symmetrical than the $\mathrm{O}_{2}$ distribution. This difference is most likely caused by the larger uncertainty in $\mathrm{O}_{2}$ fluctuations, due to the lower signal-to-noise ratio of the $\mathrm{O}_{2}$ measurements. 
(a)

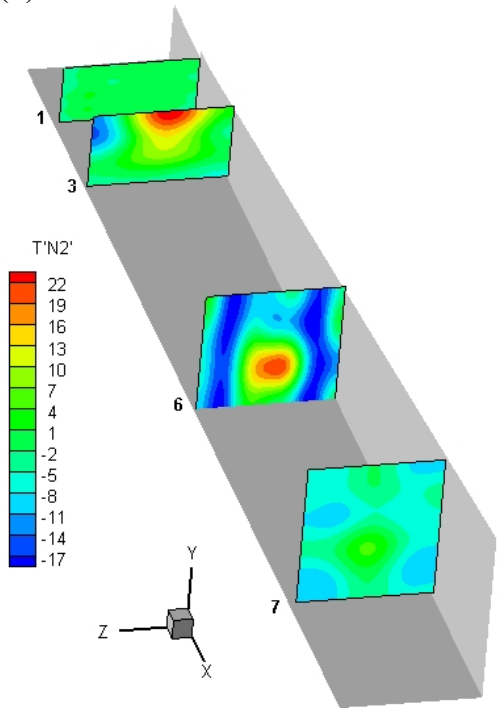

(b)

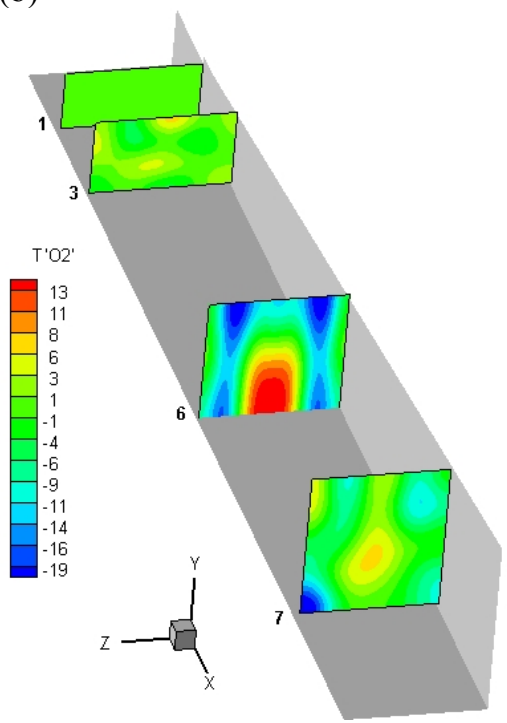

(c)

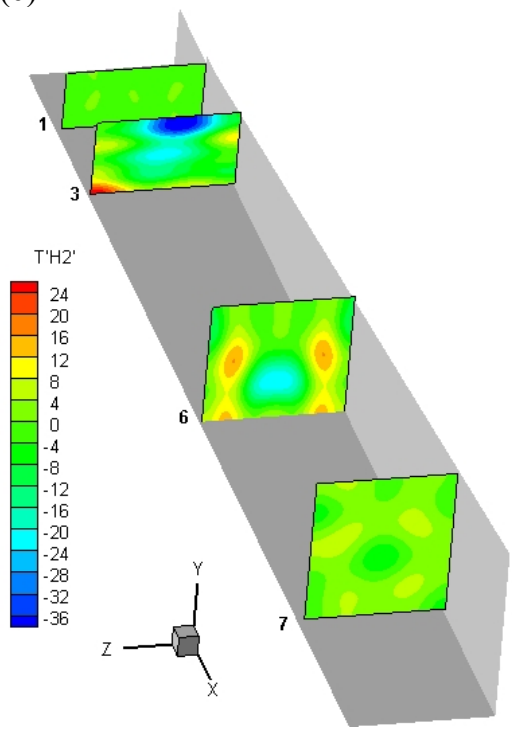

Figure 10. Temperature/mole fraction covariance maps: (a) $\left\langle T^{\prime} \chi_{\mathrm{N} 2}{ }^{\prime}\right\rangle$, (b) $\left\langle T^{\prime} \chi_{\mathrm{O}_{2}}{ }^{\prime}\right\rangle$, (c) $\left\langle T^{\prime} \chi_{\mathrm{H} 2}{ }^{\prime}\right\rangle$.

(a)

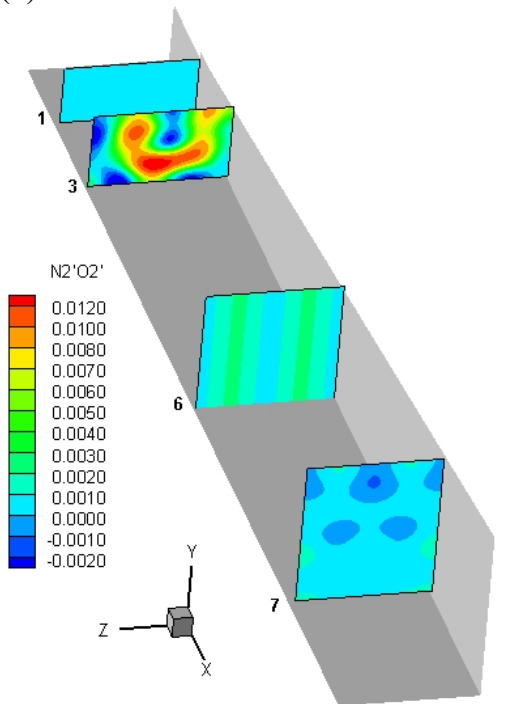

(b)

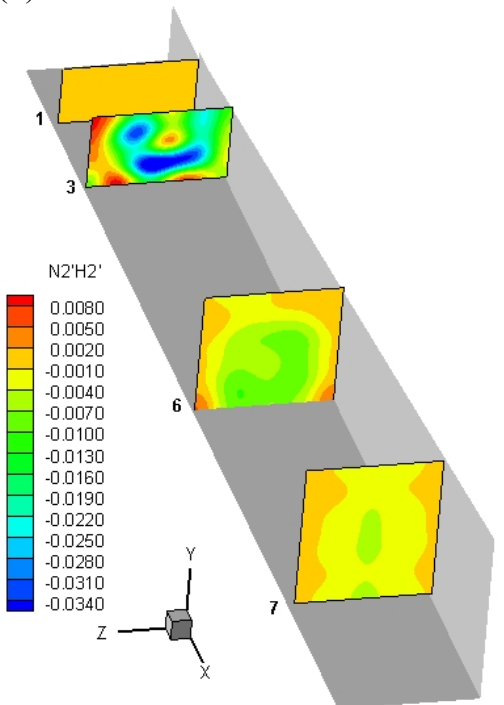

(c)

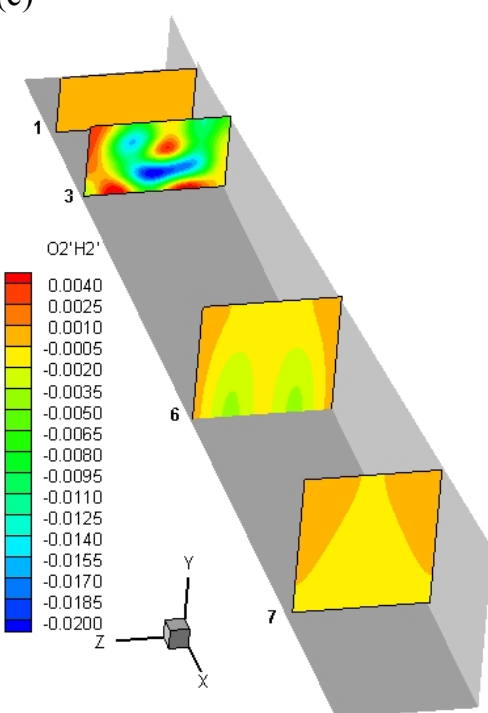

Figure 11. Mole-fraction covariance maps: (a) $\left\langle\chi_{\mathrm{N} 2} \chi_{\mathrm{O} 2}{ }^{\prime}\right\rangle$, (b) $\left\langle\chi_{\mathrm{N}^{\prime}} \chi_{\mathrm{H} 2}{ }^{\prime}\right\rangle$, , (c) $\left\langle\chi_{\mathrm{O} 2}{ }^{\prime} \chi_{\mathrm{H} 2}{ }^{\prime}\right\rangle$.

The temperature/mole-fraction covariance maps are summarized in Fig. 10. For all three temperature/mole fraction covariances, the largest fluctuations occur in plane 6 . The $\left\langle T^{\prime} \chi_{\mathrm{H} 2}{ }^{\prime}\right\rangle$ map in Fig. $10(\mathrm{c})$ plane 3 shows strong negative correlation at the top of the duct, meaning that low temperatures correspond to high mole fraction of $\mathrm{H}_{2}$ and vice-versa. Then in plane 6 the negative correlation is at the bottom of the duct while the positive correlation is at the top. The $\left\langle T^{\prime} \chi_{O 2}{ }^{\prime}\right\rangle$ and $\left\langle T^{\prime} \chi_{\mathrm{N}^{2}}{ }^{\prime}\right\rangle$ covariances in Fig. $10(\mathrm{a})$ and (b) are similar in plane 6 , and show negative correlation at the sides of the duct and positive correlation in the lower center portion of the duct. The $\left\langle T^{\prime} \chi_{\mathrm{H} 2}{ }^{\prime}\right\rangle$ map (Fig. 10(c)) shows an opposite trend. A possible explanation for this observation is that where the temperature is highest corresponds to where $\mathrm{H}_{2}$ combustion has taken place consuming all the $\mathrm{H}_{2}$ but only some of the $\mathrm{O}_{2}$ (equivalence ratio is 0.7 ).

Figure 11 contains the mole-fraction covariance maps for each of the three pairs of measured species. The $\left\langle\chi_{\mathrm{H}_{2}} \chi_{\mathrm{O} 2}{ }^{\prime}\right\rangle$ covariance is nearly always negative, indicating that $\mathrm{H}_{2}$ and $\mathrm{O}_{2}$ are anti-correlated. This is sensible since they would react if collocated. Similarly $\mathrm{N}_{2}$ and $\mathrm{O}_{2}$ are either positively correlated or uncorrelated in most of the flow. Many of the insights drawn from these plots are common sense, but the value of the plots lies in knowing the magnitude and the location in the duct where these fluctuations occur. 
Reference 19 showed that many measurements are required to measure root-mean-square temperature variations with an acceptable uncertainty in this combustor flowfield. We measured the flow properties over a fairly coarse grid in this study, as Fig. 5 illustrates. While Table 2 shows that this measurement density is sufficient for mapping mean flow properties, obtaining an acceptable uncertainty in the variances and covariances requires many more measurements. The uncertainties for the fits to these fluctuating parameters are presented in Table 3 , where the uncertainties are once again averaged over the entire plane. Table 3 shows that the measurements we present here may be under-sampled if we wish to quantitatively measure covariances with sufficient precision to enable development of turbulence models. The data is included as proof that such measurements can be made with the current system, although a larger number of measurements would be required to reduce the percentage uncertainty to acceptable levels. In their present form the measurements of fluctuation in this data are sufficient to indicate the regions in the flow where interesting fluctuations in flow properties occur.

Table 3 shows the results of the Model FStatistic and the Lack of Fit P-Statistic tests for the fluctuating quantities. Less than half of the fluctuation fitted surfaces shown Figs. 911 pass the Model FStatistic test. Passing this test indicates that there is sufficient signal-to-noise in the data to allow a good fit. Those that failed the fit indicated that more data needed to be obtained for them to have passed the test. The fact that these fits failed the tests means that there are probably small ampli-

\begin{tabular}{|c|c|c|c|c|c|c|c|c|c|c|c|c|}
\hline \multirow{2}{*}{ Parameter } & \multicolumn{3}{|c|}{ Plane 1} & \multicolumn{3}{|c|}{ Plane 3} & \multicolumn{3}{|c|}{ Plane 6} & \multicolumn{3}{|c|}{ Plane 7} \\
\hline & $\mathrm{CIHW}_{95 \%}$ & Mod. F & $\mathrm{P}$ & $\mathrm{CIHW}_{95 \%}$ & Mod. F & LOF P & $\mathrm{CIHW}_{95 \%}$ & Mod. F & LOF P & $\mathrm{CIHW}_{95 \%}$ & Mod. F & LOF P \\
\hline $\mathrm{T}^{\prime} \mathrm{T}^{\prime}$ & 1842.76 & F & $\mathrm{P}$ & 13358.05 & $\mathrm{P}$ & $\mathrm{P}$ & 21640.39 & $\mathrm{~F}$ & P & 13818.99 & $\mathrm{~F}$ & $P$ \\
\hline$\chi_{\mathrm{N}_{2}}{ }^{\prime} \chi_{\mathrm{N}_{2}}{ }^{\prime}$ & 0.00053 & $\mathrm{~F}$ & F & 0.00111 & $\mathrm{P}$ & $\mathrm{F}$ & 0.00108 & F & $\mathrm{P}$ & 0.00042 & F & $P$ \\
\hline$\chi_{\mathrm{O}_{2}}{ }^{1} \chi_{\mathrm{O}_{2}}{ }^{\prime}$ & 0.00010 & F & $P$ & 0.00339 & $\mathrm{P}$ & $\mathrm{F}$ & 0.00128 & $\mathrm{~F}$ & $\mathrm{~F}$ & 0.00063 & F & F \\
\hline$\chi_{\mathrm{H}_{2}}{ }^{2} \chi_{\mathrm{H}_{2}}{ }^{\prime}$ & 0.00008 & $\mathrm{~F}$ & F & 0.00892 & $\mathrm{P}$ & $\mathrm{P}$ & 0.00188 & $\mathrm{P}$ & $\mathrm{F}$ & 0.00075 & $\mathrm{P}$ & F \\
\hline$T^{\prime} \chi_{\mathrm{N}_{2}}{ }^{\prime}$ & 0.69779 & F & $\mathrm{P}$ & 3.41999 & $\mathrm{P}$ & F & 4.70544 & $\mathrm{P}$ & $\mathrm{P}$ & 2.04252 & F & $\mathrm{P}$ \\
\hline $\mathrm{T}^{\prime} \chi_{\mathrm{O}_{2}}{ }^{\prime}$ & 0.19904 & $\mathrm{~F}$ & $\mathrm{P}$ & 1.81627 & F & $\mathrm{P}$ & 3.73716 & $\mathrm{P}$ & $\mathrm{P}$ & 2.49490 & $\mathrm{~F}$ & $\mathrm{P}$ \\
\hline $\mathrm{T}^{\prime} \chi_{\mathrm{H}_{2}}{ }^{\prime}$ & 0.25387 & $\mathrm{~F}$ & $\mathrm{~F}$ & 6.12454 & F & $\mathrm{F}$ & 4.55656 & F & $\mathrm{F}$ & 1.82439 & $\mathrm{~F}$ & P \\
\hline$\chi_{\mathrm{N}_{2}}{ }^{1} \chi_{\mathrm{O}_{2}}{ }^{\prime}$ & 0.00009 & $\mathrm{~F}$ & $\mathrm{P}$ & 0.00175 & $\mathrm{P}$ & $\mathrm{F}$ & 0.00039 & $\mathrm{~F}$ & $\mathrm{P}$ & 0.00037 & F & $\mathrm{P}$ \\
\hline$\chi_{\mathrm{N}_{2}}{ }^{\prime} \chi_{\mathrm{H}_{2}}{ }^{\prime}$ & 0.00003 & $\mathrm{~F}$ & $\mathrm{~F}$ & 0.00499 & $\mathrm{P}$ & $\mathrm{F}$ & 0.00127 & $\mathrm{P}$ & $\mathrm{F}$ & 0.00054 & $\mathrm{P}$ & $\mathrm{P}$ \\
\hline$\chi_{\mathrm{O}_{2}}{ }^{\prime} \chi_{\mathrm{H}_{2}}{ }^{\prime}$ & 0.00001 & $\mathrm{~F}$ & $\mathrm{~F}$ & 0.00263 & $P$ & $\mathrm{~F}$ & 0.00068 & $\mathrm{~F}$ & $\mathrm{~F}$ & 0.00028 & $\mathrm{~F}$ & $\mathrm{P}$ \\
\hline
\end{tabular}

Table 3. Statistical $95 \%$ confidence interval half width uncertainties $\left(\mathrm{CIHW}_{95 \%}\right)$ in fitted surfaces, and results of the Model F-statistic (Mod. F) and Lack of Fit P-statistic (LOF-P) tests. "P" and "F" indicate pass and fail, respectively. Note that statistical uncertainties do not account for systematic errors in measured quantities.

tude variations shown in the graphs that are not real - rather they are fitting to noise. Nonetheless, the larger features shown in the surfaces are real. Furthermore, a little more than half of the surface fits failed the Lack-of-fit $P$-Statistic test. As above, choosing different fit functions can result is satisfactory fits, but we did not do so, to avoid introducing another variable into the analysis. Acquiring substantially more data might also allow this second test to be passed.

\section{Conclusions}

We have used the dual-pump CARS measurement technique to simultaneously measure temperature and the mole fraction of $\mathrm{O}_{2}, \mathrm{~N}_{2}$ and $\mathrm{H}_{2}$ in a model supersonic combustor, though the $\mathrm{H}_{2}$ mole fraction measurements are presently considered to be qualitative. Nearly eight thousand single-shot measurements were obtained in 4 different measurement planes oriented perpendicular to the flow. These measurements were fit with analytic surfaces to provide two-dimensional maps of each mean flow properties in each of the four planes. The maps were used, together with the raw data, to compute fluctuating quantities and their correlations, including $\left\langle T^{\prime} T^{\prime}\right\rangle,\left\langle T^{\prime} \chi_{H 2}{ }^{\prime}\right\rangle$, and $\left\langle\chi_{\mathrm{H} 2} \chi_{\mathrm{N} 2}{ }^{\prime}\right\rangle$, among others. This type of data should be useful for developing new models to predict turbulent flow, mixing and combustion.

The data presented here shows combustion beginning at the top of the duct, being strongest at the top and spreading towards the bottom of the duct as the flow proceeds downstream. Comparing the present normal fuel injection case to a previously published vectored fuel injection case, a large difference in the onset of combustion can be seen: the normal fuel injection case has combustion that starts further upstream. Examination of the intensity of fluctuations about the mean allow us to determine where significant mixing and combustion are occurring in the flowfield.

The CARS system, analysis and application described above could be improved in several ways. First, the observed errors in $\mathrm{H}_{2}$ mole fraction should be investigated. Gas-cell experiments performed for various temperatures and species compositions should aid in determining whether a modeling error exists or whether there are other problems with the technique. If a modeling error is confirmed, the spectral modeling of $\mathrm{H}_{2}$ would be carefully scrutinized to determine how the error may be removed. Second, a direct measurement of the $\mathrm{H}_{2} \mathrm{O}$ mole fraction using a different pump laser dye in the same configuration should be developed. Inferred $\mathrm{H}_{2}$ concentrations could then be directly compared with the values measured using the current system. Third, the combination of an 
injection-seeded YAG laser and modeless dye laser could be used to improve the precision of all the measurements, perhaps by a factor of two or more. This would help reduce the amount of data required to accurately determine mean and turbulence statistical properties, compared to the existing system. More data could also be acquired to further enhance measurement precision. Fourth, a robust algorithm of the sequential fitting method could be written to assure the best quality fit.

\section{Acknowledgements}

We wish to acknowledge the assistance of Diego Capriotti from NASA Langley Research Center for coordinating the running of the facility and processing of pressure data for this paper. We also thank Jeff White from NASA Langley Research Center who assisted us in computing libraries of CARS spectra on a large cluster of personal computers, significantly decreasing the computational time.

\section{References}

${ }^{1}$ Yang, S.R., Zhau, J.R., Sung, G.J. and Yu, G., "Simultaneous multiplex CARS measurements of temperature and concentrations of $\mathrm{O} 2$ and $\mathrm{H} 2$ in supersonic hydrogen-air combustion," AIAA98-0727, $36^{\text {th }}$ Aerospace Sciences Meeting, Reno, Nevada, USA, January 12-15, 1998.

${ }^{2}$ Grisch, F., Bouchardy, P. and Clauss, W., "CARS Thermometry in high pressure rocket combustors," Aerospace Science and Technology, Vol. 7, 2003, pp. 317-330.

${ }^{3}$ Anderson, T.J. and Eckbreth, A.C., "Simultaneous CARS measurements of temperature and $\mathrm{H}_{2}, \mathrm{H}_{2} \mathrm{O}$ concentration in hydrogen-fueled supersonic combustion", AIAA Paper 90-0158, $28^{\text {th }}$ Aerospace Sciences Meeting, January 1990.

${ }^{4}$ Weisgerber, H., Fischer, M., Magens, E., Winandy, A., Foerster, W., Beversdorff, M., "Experimental analysis of the flow of exhaust gas in a hypersonic nozzle," AIAA Paper 98-1600, $8^{\text {th }}$ International Space Planes and Hypersonic Systems and Technologies Conference, Norfolk, Virginia, USA, 27-30 April, 1998.

${ }^{5}$ Vereschagin, K.A., Smirnov, V.V., Stelmakh, O.M., Fabelinski, V.I., Sabelnikov, V.A., Ivanov, V.V., Clauss, W. and Oschwald, M., "Temperature measurements by coherent anti-Stokes Raman spectroscopy in hydrogen-fuelled scramjet combustor," Aerospace Science and Technology, Vol. 5, 2001, pp. 347-355.

${ }^{6}$ Cutler, A.D., Danehy, P.M., Springer, R.R., O’Byrne, S., Capriotti, D.P., DeLoach, R., "Coherent Anti-Stokes Raman Spectroscopic Thermometry in a Supersonic Combustor," AIAA J., Vol. 41, No. 12, Dec. 2003. (Also, AIAA Paper 2002-0743.)

${ }^{7}$ Smith, M.W., Jarrett, O. Jr., Antcliff R.R., Northam, G.B., Cutler, A.D. and Taylor, D.J., "Coherent anti-Stokes Raman spectroscopy temperature measurements in a hydrogen-fueled supersonic combustor," Journal of Propulsion and Power, Vol. 9, No. 2, 1993, pp. $163-168$.

8 O'Byrne, S., Danehy, P.M., Cutler, A.D., "Dual-Pump CARS Thermometry and Species Concentration Measurements in a Supersonic Combustor," AIAA Paper 2004-0710, 42 ${ }^{\text {nd }}$ Aerospace Sciences Meeting and Exhibit, Reno, NV, January 5-8, 2004.

9 Rodriguez, C.G., Cutler, A.D., "CFD Analysis of the SCHOLAR Scramjet Model," AIAA Paper 2003-7039, AIAA $12^{\text {th }}$ International Space Planes \& Hypersonic Systems \& Technologies Conference, Norfolk, VA, 15-19 Dec. 2003.

${ }^{10}$ Lucht, R.P., "Three-laser coherent anti-Stokes Raman scattering measurements of two species," Optics Letters, Vol. 12, No. 2, February 1987, pp. 78-80.

${ }^{11}$ Hancock, R.D., Schauer, F.R., Lucht, R.P. and Farrow, R.L., "Dual-pump coherent anti-Stokes Raman scattering measurements of nitrogen and oxygen in a laminar jet diffusion flame," Applied Optics, Vol. 36, No. $15,1997$.

${ }^{12}$ Danehy, P.M., O’Byrne, S., Cutler, A.D. and Rodriguez, C.G., "Coherent anti-Stokes Raman scattering (CARS) as a probe for supersonic hydrogen-fuel/air mixing," JANNAF APS/CS/PSHS/MSS Joint Meeting, Colorado Springs, Colorado, December 1-5, 2003.

${ }^{13}$ Auslender, A. H., "An application of distortion analysis to scramjet combustor performance assessment," Final Report, 1996 JANNAF Propulsion and Joint Subcommittee meeting Scramjet Performance Workshop, December $12,1996$.

${ }^{14}$ Springer, R. R., Cutler, A. D., Diskin, G. S., Smith, M. W., "Conventional/laser diagnostics to assess flow quality in a combustion-heated facility," AIAA Paper 99-2170, 35 ${ }^{\text {th }}$ AIAA/ASME/SAE/ASEE Joint Propulsion Conference and Exhibit, Los Angeles, CA, June 20-24, 1999.

${ }^{15}$ Palmer, R.E., "The CARSFT computer code for calculating coherent anti-Stokes Raman spectra: user and programmer information," Sandia National Laboratories Report SAND89-8206, Livermore, California, 1989. 
16 O’Byrne, S., Danehy, P.M., Cutler, A.D., "N2/O2/H2 dual-pump CARS: validation experiments," 20 $0^{\text {th }}$ International Congress on Instrumentation in Aerospace Simulation Facilities, Göttingen, Germany, August 25-29, 2003.

${ }^{17}$ Dicke, R.H., "The effect of collisions upon the Doppler width of spectral lines," Physical Review, Vol. 89, 1953, pp. 472-473.

${ }^{18}$ Danehy, P.M., DeLoach, R., Cutler, A.D., "Application of modern design of experiments to CARS thermometry in a model scramjet engine," AIAA Paper 2002-2914, 22 ${ }^{\text {nd }}$ AIAA Aerodynamic Measurement Technology and Ground Testing Conference, St. Louis, Missouri, USA, June 24-26, 2002.

${ }^{19}$ Danehy, P.M., Dorrington, A.A., Cutler, A.D. and DeLoach, R., "Response surface methods for spatially-resolved optical measurement techniques," AIAA 2003-0648, 41 ${ }^{\text {st }}$ Aerospace Sciences Meeting and Exhibit, Reno, Nevada, January 2003.

${ }^{20}$ Kraber, S., Handbook for Experimenters, Stat-Ease: Minneapolis, MN, Version 06.8, 2002, pp.3-20. 